\title{
Multiloop Interleaved Control for Three-Level Switch-Mode Rectifier in AC/DC Applications
}

\author{
Hung-Chi Chen, Member, IEEE, and Jhen-Yu Liao
}

\begin{abstract}
In this paper, multiloop interleaved control (MIC) is proposed, and it is combined with conventional multiloop control and the interleaved pulsewidth modulation scheme. The average behavior of the interleaved three-level switch-mode rectifier (SMR) behaves similar to the conventional boost-type SMR even though two capacitor voltages are imbalanced. It implies that conventional multiloop control can be applied to the interleaved three-level SMRs to achieve the desired power factor correction function. The proposed MIC is digitally implemented and verified in a field-programmable-gate-array-based system. The provided results show that MIC stably works and the capacitor voltages are eventually balanced during the system operations.
\end{abstract}

Index Terms-Interleaved control, three-level boost switchmode rectifier (SMR).

\section{INTRODUCTION}

$\mathbf{W}$ ITH THE increase in power electronics products, the power factor correction (PFC) function becomes important [1]. Generally speaking, the PFC function includes shaping the current waveform and regulating the output voltage. Due to the continuous input current, the boost-type converter has been widely integrated to the switch-mode rectifier (SMR) shown in Fig. 1(a) to achieve the desired PFC function [2]. The gate signal $G T$ is obtained from the comparison of controller output signal $v_{\text {cont }}$ and sawtooth signal $v_{\text {tri }}$.

As shown in Fig. 1(b), the conventional multiloop control includes an inner current loop and an outer voltage loop, and it is often used to generate the gate signal for the conventional boost-type SMR. One inductor current signal is fed back to the inner current loop to shape the current waveform. The output voltage is sensed for the outer voltage loop to regulate the output voltage. Sensing input voltage is also required for the generation of the desired current reference [3], [4] and the feedforward terms [5], [6]. In [7] and [8], some compensation loops are added to the multiloop control to improve the PFC performance for motor drive applications. For the boost converter, the single switch needs to withstand the overall output voltage when the switch blocks.

The three-level boost converter is shown in Fig. 2 where two capacitors are connected across the switches, respectively.

Manuscript received December 9, 2012; revised February 17, 2012, April 3, 2013, and June 14, 2013; accepted July 24, 2013. Date of publication August 16, 2013; date of current version January 31, 2014. This work was supported by the Ministry of Economic Affairs of Taiwan under Contract 99EC-17-A-05-S1-154.

The authors are with the Department of Electrical and Computer Engineering, National Chiao Tung University, Hsinchu 300, Taiwan (e-mail: hcchen@ cn.nctu.edu.tw; id1003.ece99g@g2.nctu.edu.tw).

Color versions of one or more of the figures in this paper are available online at http://ieeexplore.ieee.org.

Digital Object Identifier 10.1109/TIE.2013.2278961

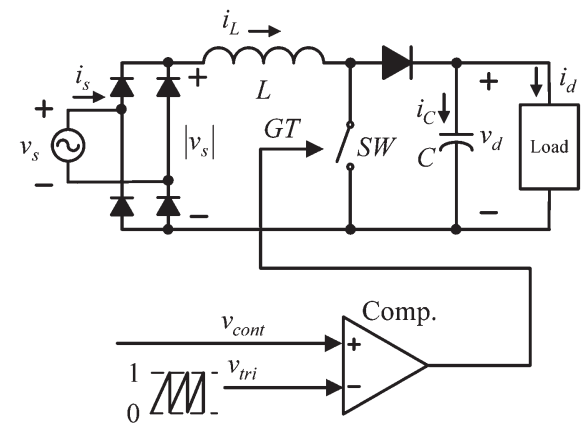

(a)

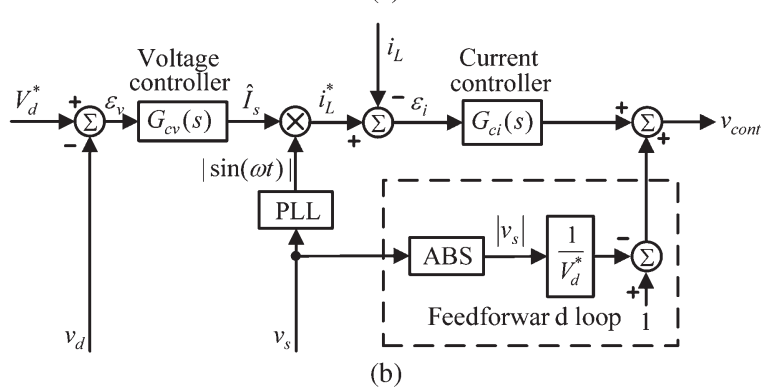

Fig. 1. (a) Conventional boost-type SMR. (b) Multiloop control with feedforward loop [5], [6].

Thus, each switch needs to withstand only a half output voltage. In addition, the inductor voltage in the three-level boost converter has three levels, but the inductor voltage in the conventional boost converter has only two levels.

Therefore, the three-level boost converter is able to yield smaller inductor current ripple than the conventional boost converter. It follows that three-level converters are often used in the applications, such as the high-voltage-ratio dc/dc conversion [9]-[12] and the wide input voltage range [13], particularly in the fuel cell applications [11], [13] and the grid-connected applications [10], [14], [15].

Additionally, the high-withstanding-voltage semiconductor switches often have larger drain-source resistances than the low-withstanding-voltage ones. Thus, the three-level converter has the advantages of low voltage stress, small inductor current ripple, and low switching loss [1], [11], [16].

In Fig. 2, the three-level SMR was obtained by connecting the diode rectifier with the three-level converter [16]-[20]. In [17], the three single-phase three-level SMRs are in Delta connection to achieve the three-phase PFC function with the ability of redundancy.

The control methods for the three-level SMR (ac/dc application) can be found in [18]-[20] where gate signals GT1 and GT2 are generated from the lookup table with inputs $H_{1}, H_{2}$, and $H_{3}$. 


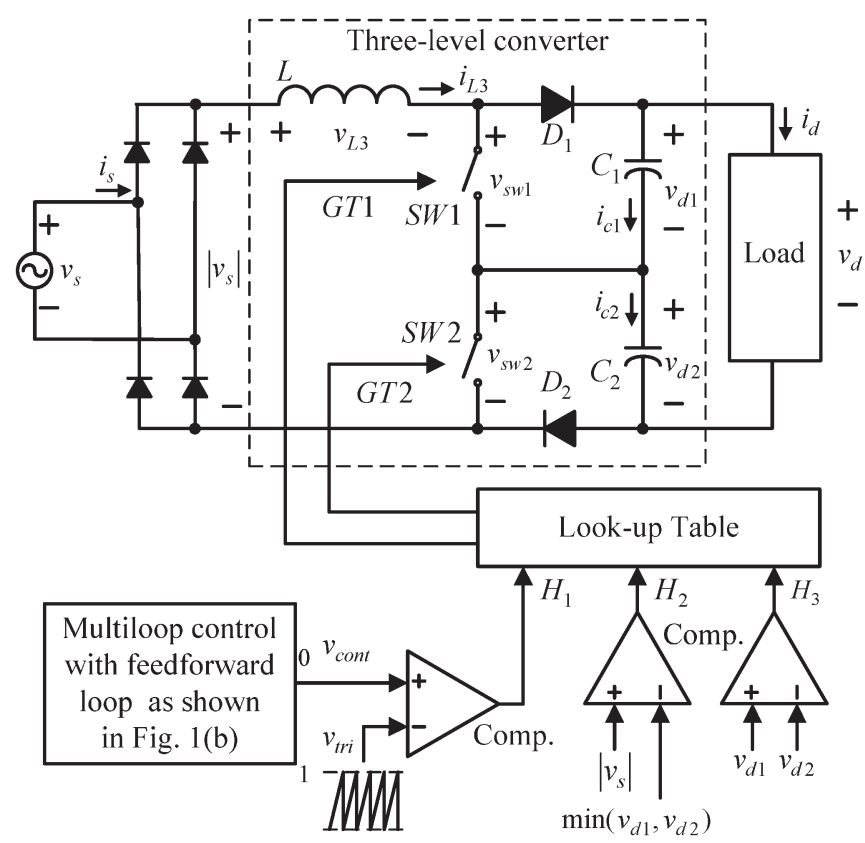

Fig. 2. Three-level SMR and its conventional control [17]-[19].

Comparative signal $H_{1}$ is generated from the comparison of the conventional multiloop output $v_{\text {cont }}$ and sawtooth signal $v_{\text {tri }}$, and signal $H_{1}$ is the same as gate signal $G T$ in Fig. 1. The table input $H_{2}$ is the comparison output to show whether the absolute input voltage $\left|v_{s}\right|$ is lower or higher than the minimum one of capacitor voltages $v_{d 1}$ and $v_{d 2}$. The input $H_{3}$ is used to indicate which capacitor voltage is higher than the other.

It can be found that sensing capacitor voltage is required for the generation of inputs $\mathrm{H}_{2}$ and $\mathrm{H}_{3}$. Therefore, for the control of the three-level SMR, it is necessary to sense individual capacitor voltage and to add voltage balancing loop in [18][20]. Similar voltage balancing loops can be also found in the dc/dc applications [11], [12], [14], [15], [21].

In this paper, the average behavior of a three-level SMR under the interleaved pulsewidth modulation (PWM) scheme [22]-[24] (i.e., interleaved three-level SMR) is derived. The interesting result shows that the interleaved three-level SMR behaves similar to a conventional boost-type SMR even when the two capacitor voltages are imbalanced. It means that the multiloop control and the interleaved PWM scheme can be integrated to achieve the desired PFC function without an additional voltage balancing loop. Thus, the proposed multiloop interleaved control (MIC) is simpler than the control method in Fig. 2.

From the provided simulation and experimental results, the proposed MIC is able to achieve PFC functions, and in particular, the three-level SMR in ac/dc application is able to take several seconds to balance the capacitor voltages without the voltage balancing control loop. However, because the time taken to balance the voltages is long, the voltage balancing loop is sometimes required.

\section{Conventional Boost-Type SMR}

In first, the average inductor voltage and the current ripple of the conventional boost-type SMR in Fig. 1 is studied for comparison. The input voltage $v_{s}=\hat{V}_{s} \sin (2 \pi f t)$ is assumed to be a sinusoidal function with peak amplitude $\hat{V}_{s}$. Through the diode rectifier, the input voltage of a boost converter can be expressed by an absolute function $\left|v_{s}\right|$.

By assuming that switching frequency $f_{s}$ is much larger than line frequency $f$, the control signal $v_{\text {cont }}$ within each switching period $T_{s}=1 / f_{s}$ can be regarded as a constant. Then, in Fig. 1, the operating duty ratio of the switch is equal to $v_{\text {cont }}$ due to the unity sawtooth signal $v_{\text {tri }}$. It means that the conducting time and the blocking time of the switch can be expressed as $v_{\text {cont }} T_{s}$ and $\left(1-v_{\text {cont }}\right) T_{s}$, respectively.

\section{A. Average Inductor Voltage}

When the switch conducts in Fig. 1, inductor voltage $v_{L}$ equals the rectified input voltage $\left|v_{s}\right|$. Once the switch blocks, inductor voltage $v_{L}$ equals the difference between the rectified input voltage $\left|v_{s}\right|$ and output voltage $v_{d}$, i.e., $v_{L}=\left|v_{s}\right|-v_{d}$. Then, the average inductor voltage $\left\langle v_{L}\right\rangle_{T s}$ within each switching period $T_{s}$ can be expressed by

$$
\left\langle v_{L}\right\rangle_{T s}=\frac{\left[\begin{array}{l}
\left|v_{s}\right| v_{\text {cont }} T_{s} \\
+\left(\left|v_{s}\right|-v_{d}\right)\left(1-v_{\text {cont }}\right) T_{s}
\end{array}\right]}{T_{s}}=\left|v_{s}\right|-\left(1-v_{\text {cont }}\right) v_{d} .
$$

The input voltage of the boost converter is equal to the rectified input voltage $\left|v_{s}\right|=\hat{V}_{s}|\sin (2 \pi f t)|$. By assuming that output voltage $v_{d}$ is well regulated to voltage command $V_{d}^{*}$, duty ratio $v_{\text {cont }}$ can be expressed as

$$
v_{\mathrm{cont}}=1-\frac{\hat{V}_{s}|\sin (2 \pi f t)|}{V_{d}^{*}} .
$$

\section{B. Inductor Current Ripple}

When the switch conducts, the inductor voltage is equal to the rectified input voltage $v_{L}=\left|v_{s}\right|$. Thus, the rising rate of the inductor current is $\left|v_{s}\right| / L$. Similarly, the falling rate of the current is $\left(\left|v_{s}\right|-v_{d}\right) / L$ when the switch blocks. Therefore, within each switching period $T_{s}$, inductor current ripple $\Delta i_{L}$ can be expressed by either the current rising rate or the current falling rate. Thus

$$
\begin{aligned}
& \Delta i_{L}=\frac{\left|v_{s}\right|}{L} v_{\text {cont }} T_{s}=\frac{\left|v_{s}\right|}{L f_{s}} v_{\text {cont }} \\
& \Delta i_{L}=\frac{\left|v_{s}\right|-v_{d}}{L}\left(1-v_{\text {cont }}\right) T_{s}=\frac{\left|v_{s}\right|-v_{d}}{L f_{s}}\left(1-v_{\text {cont }}\right) .
\end{aligned}
$$

By combining (3) and (4) and eliminating the term $\left|v_{s}\right|$, the expression of current ripple $\Delta i_{L}$ can be obtained by

$$
\begin{aligned}
\Delta i_{L} & =\frac{v_{d}}{L f_{s}}\left(1-v_{\text {cont }}\right) v_{\text {cont }} \\
& =-\frac{v_{d}}{L f_{s}}\left(v_{\text {cont }}-\frac{1}{2}\right)^{2}+\frac{v_{d}}{4 L f_{s}} \leq \frac{v_{d}}{4 L f_{s}} .
\end{aligned}
$$

It is clear that the maximum current ripple $\Delta i_{L, \max }=$ $v_{d} /\left(4 L f_{s}\right)$ occurs at the duty ratio $v_{\text {cont }}=1 / 2$, and the minimum current ripple is zero, i.e., $\Delta i_{L, \min }=0$, when the control signal equals either $v_{\text {cont }}=1$ or $v_{\text {cont }}=0$. 


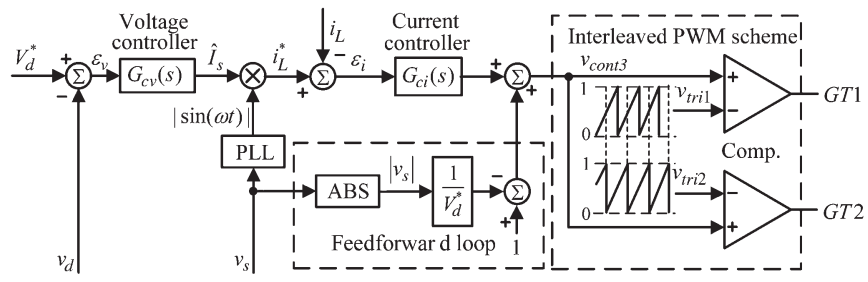

Fig. 3. Proposed MIC for three-level SMR.

\section{Output Voltage}

When the switch conducts, the diode current is zero, i.e., $i_{D}(t)=0$, and when the switch blocks, diode current $i_{D}(t)$ is equal to the inductor current, i.e., $i_{D}(t)=i_{L}(t)$. Then, the average diode current $\left\langle i_{D}\right\rangle_{T s}$ within switching period $T_{s}$ can be expressed in terms of duty ratio $v_{\text {cont }}$ and the average inductor current $\left\langle i_{L}\right\rangle_{T s}$. Thus

$$
\left\langle i_{D}\right\rangle_{T_{s}}=\left(1-v_{\mathrm{cont}}\right)\left\langle i_{L}\right\rangle_{T_{s}}
$$

Assume that the average inductor current $\left\langle i_{L}\right\rangle_{T s}$ is well controlled to follow the rectified sinusoidal waveform $\left\langle i_{L}\right\rangle_{T s}=$ $\hat{I}_{s}|\sin (2 \pi f t)|$ in phase with input voltage $v_{s}(t)$. Then, by combining (2) and (6), the average diode current $\left\langle i_{D}\right\rangle_{T s}$ can be rewritten as

$$
\left\langle i_{D}\right\rangle_{T s}=\frac{\hat{V}_{s} \hat{I}_{s} \sin (2 \pi f t)^{2}}{V_{d}^{*}}=\frac{\hat{V}_{s} \hat{I}_{s}}{2 V_{d}^{*}}-\frac{\hat{V}_{s} \hat{I}_{s}}{2 V_{d}^{*}} \cos (4 \pi f t) .
$$

It is clear that the second term in (7) is an ac component with double line frequency, and it must flow through capacitor $C$. Thus, the average capacitor current $\left\langle i_{C}\right\rangle_{T_{s}}$ is equal to

$$
\left\langle i_{C}\right\rangle_{T s}=-\frac{\hat{V}_{s} \hat{I}_{s}}{2 V_{d}^{*}} \cos (4 \pi f t)
$$

The average capacitor current $\left\langle i_{C}\right\rangle_{T_{s}}$ flowing through capacitor $C$ yields the following average voltage ripple $\left\langle v_{\text {rip }}\right\rangle_{T s}$ :

$$
\left\langle v_{\text {rip }}\right\rangle_{T s} \approx \frac{1}{C} \int\left\langle i_{C}\right\rangle_{T s} d t=-\frac{\hat{V}_{s} \hat{I}_{s}}{8 \pi f C V_{d}^{*}} \sin (4 \pi f t) .
$$

Then, the average output voltage can be roughly expressed as

$$
\left\langle v_{d}\right\rangle_{T s} \approx V_{d}^{*}+\left\langle v_{\text {rip }}\right\rangle_{T s}=V_{d}^{*}-\frac{\hat{V}_{s} \hat{I}_{s}}{8 \pi f C V_{d}^{*}} \sin (4 \pi f t) .
$$

\section{MIC}

The proposed MIC shown in Fig. 3 combines the conventional multiloop control, the feedforward loop, and the interleaved PWM scheme. Both the voltage controller and the current controller are proportional-integral-type controllers. Two gate signals $G_{T 1}$ and $G_{T 2}$ are generated from the comparisons of control signal $v_{\text {cont } 3}$ and two unit sawtooth signals $v_{\text {tri1 }}$ and $v_{\text {tri2 }}$, respectively. It is noted that the two sawtooth signals have unit amplitude and identical period $T_{s}$; however, there is a $180^{\circ}$ phase difference between them. Both duty ratios of switches $S W 1$ and $S W 2$ are equal to the MIC control signal $v_{\text {cont3 } 3}$.

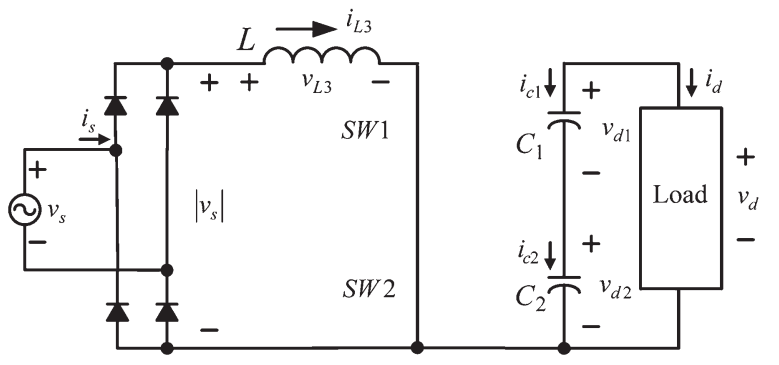

(a)

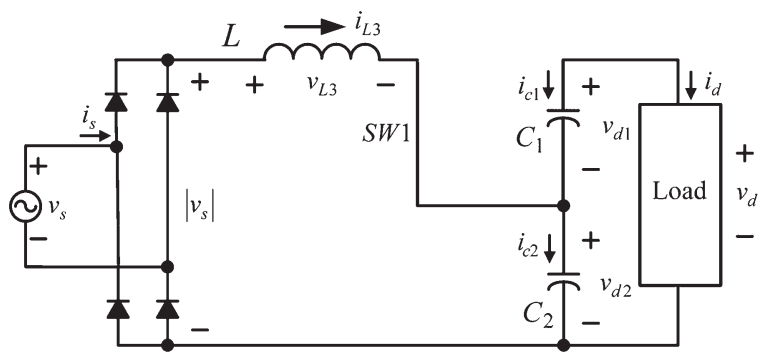

(b)

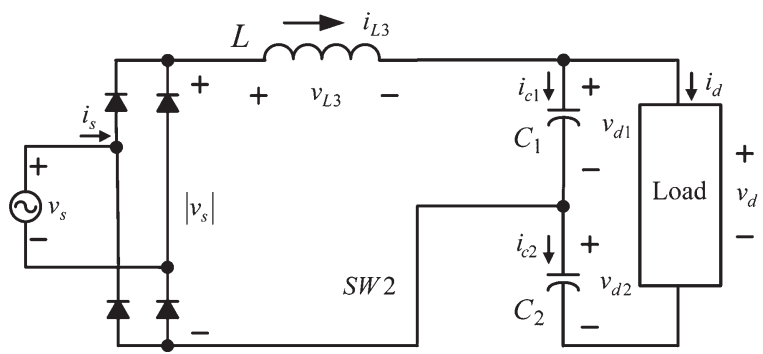

(c)

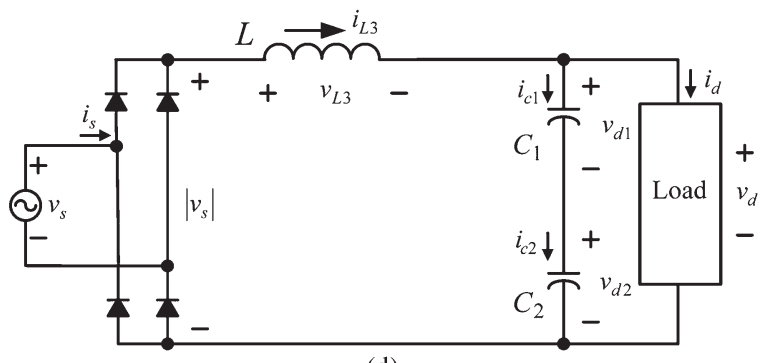

(d)

Fig. 4. Possible switching states in the interleaved three-level SMR. (a) State 1. (b) State 2. (c) State 3. (d) State 4.

Due to input inductor $L$ and diodes $D_{1}$ and $D_{2}$ in the threelevel SMR, both switches are turned on at the same time. Therefore, there are four possible switching states in the operation of the interleaved three-level SMR, and they are plotted in Fig. 4.

As shown in Fig. 4(a), both switches turn on at switching state 1. Thus, inductor voltage $v_{L 3}$ in the three-level SMR equals the rectified input voltage $v_{L 3}=\left|v_{s}\right|$, and both capacitors supply energy to the load $i_{C 1}=i_{C 2}=-i_{d}$. At switching state 2 plotted in Fig. 4(b), the upper switch turns on, and the lower switch turns off. The resulting inductor voltage $v_{L 3}=$ $\left|v_{s}\right|-v_{d 2}$ equals the difference between the rectified input voltage $\left|v_{s}\right|$ and capacitor voltage $v_{d 2}$. Additionally, capacitor $C_{1}$ supplies energy to the load $i_{C 1}=-i_{d}$; however, capacitor $C_{2}$ stores the energy from input source $i_{C 2}=i_{L 3}-i_{d}$.

Similarly, the resulting inductor voltage in Fig. 4(c) is equal to the rectified input voltage minus the upper capacitor voltage $v_{L 3}=\left|v_{s}\right|-v_{d 1}$. At switching state 3, the upper capacitor 


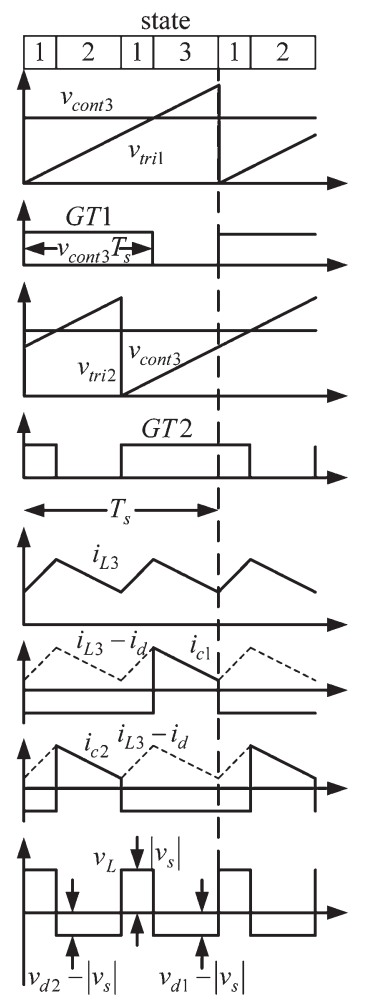

(a)

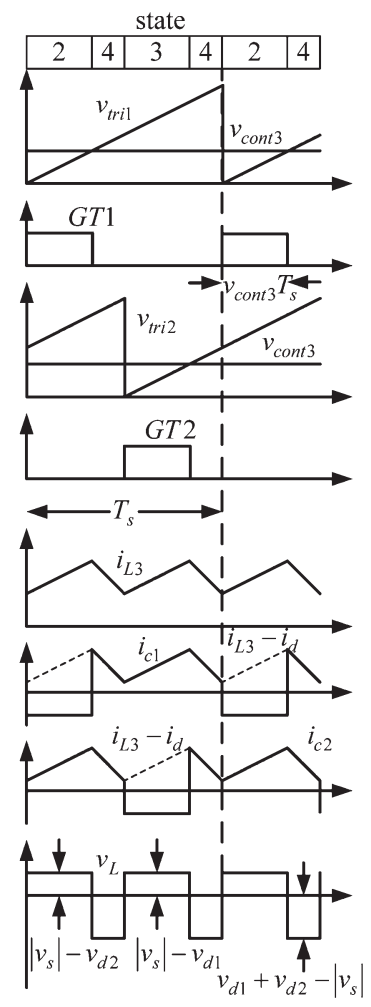

(b)
Fig. 5. Illustrated waveforms for (a) $v_{\text {cont }}>0.5$ and (b) $v_{\text {cont }}<0.5$.

$C_{1}$ is charging $i_{C 1}=i_{L 3}-i_{d}$, but the lower capacitor $C_{2}$ is discharging $i_{C 2}=-i_{d}$.

When both switches turn off in Fig. 4(d), the resulting inductor voltage equals the rectified input voltage minus the output voltage $v_{L 3}=\left|v_{s}\right|-v_{d}=\left|v_{s}\right|-v_{d 1}-v_{d 2}$. The rectified input voltage $\left|v_{s}\right|$ supplies the load and charges both capacitors $i_{C 1}=i_{C 2}=i_{L 3}-i_{d}$.

The analysis of the three-level converter can be divided into two conditions. One condition is $v_{\text {cont } 3}>0.5$, and the other condition is $v_{\text {cont } 3}<0.5$. Both illustrated waveforms are plotted in Fig. 5.

\section{A. Average Inductor Voltage}

$v_{\text {cont3 }}>0.5$ : When control signal $v_{\text {cont3 }}$ is larger than 0.5 , both duty ratios of the switches are larger than 0.5 , and their conducting times are $v_{\text {cont } 3} T_{s}$. However, there is a time difference $T_{s} / 2$ between their turning-on instants. Therefore, the times taken by switching state 2 and switching state 3 are $\left(1-v_{\text {cont3 } 3}\right) T_{s}$. The remaining time for switching state 1 is $\left(2 v_{\text {cont3 }}-1\right) T_{s}$ because each switching period is $T_{s}$.

By applying the average method, the average inductor voltage $\left\langle v_{L 3}\right\rangle_{T s}$ in this condition can be expressed as

$$
\begin{aligned}
& \left|v_{s}\right|\left(2 v_{\text {cont } 3}-1\right) T_{s} \\
& +\left(\left|v_{s}\right|-v_{d_{1}}\right)\left(1-v_{\text {cont } 3}\right) T_{s} \\
& \left\langle v_{L 3}\right\rangle_{T s}=\frac{+\left(\left|v_{s}\right|-v_{d 2}\right)\left(1-v_{\mathrm{cont} 3}\right) T_{s}}{T_{s}} \\
& =\left|v_{s}\right|-\left(1-v_{\text {cont } 3}\right)\left(v_{d 1}+v_{d 2}\right)=\left|v_{s}\right|-\left(1-v_{\text {cont } 3}\right) v_{d}
\end{aligned}
$$

where output voltage $v_{d}$ is the sum of the two capacitor voltages $v_{d}=v_{d 1}+v_{d 2}$.

$v_{\text {cont }}<0.5$ : As shown in Fig. 5(b), both duty ratios of the switches are smaller than 0.5 , and both times taken by switching state 2 and switching state 3 are $v_{\text {cont } 3} T_{s}$. Thus, the time for state 4 is $\left(1-2 v_{\text {cont3 } 3}\right) T_{s}$. It follows that the average inductor voltage $\left\langle v_{L 3}\right\rangle_{T s}$ in this condition is

$$
\begin{aligned}
& \left(\left|v_{s}\right|-v_{d_{1}}\right) v_{\mathrm{cont} 3} T_{s} \\
& +\left(\left|v_{s}\right|-v_{d 2}\right) v_{\text {cont } 3} T_{s} \\
& \left\langle v_{L 3}\right\rangle_{T s}=\frac{+\left(\left|v_{s}\right|-v_{d}\right)\left(1-2 v_{\mathrm{cont} 3}\right) T_{s}}{T_{s}} \\
& =\left|v_{s}\right|-\left(1-v_{\mathrm{cont} 3}\right) v_{d} .
\end{aligned}
$$

From (11) and (12), it can be found that whether control signal $v_{\text {cont3 }}$ is larger or smaller than 0.5 , the average inductor voltage $\left\langle v_{L 3}\right\rangle_{T s}$ is always equal to $\left\langle v_{L 3}\right\rangle_{T s}=\left|v_{s}\right|-$ $\left(1-v_{\text {cont3 } 3}\right) v_{d}$ even though two capacitor voltages are imbalanced $v_{d 1} \neq v_{d 2}$. Additionally, the result $\left\langle v_{L 3}\right\rangle_{T s}=\left|v_{s}\right|-$ $\left(1-v_{\text {cont } 3}\right) v_{d}$ is the same as the average inductor voltage (1), which shows that the three-level SMR behaves similar to a conventional boost-type SMR even though two capacitor voltages are imbalanced. Therefore, the conventional multiloop control in Fig. 1(b) can be integrated into the proposed MIC to achieve the same PFC function for the three-level SMR. Due to the same average inductor voltage $\left\langle v_{L 3}\right\rangle_{T s}$, the control signal $v_{\text {cont }}$ by the multiloop control in (2) can be extended to the MIC control signal $v_{\text {cont3 }}$, i.e.,

$$
v_{\text {cont3 }}=v_{\text {cont }}=1-\frac{\hat{V}_{s}|\sin (2 \pi f t)|}{V_{d}^{*}} .
$$

\section{B. Output Voltage and Capacitor Voltages}

When switch $S W 1$ in Fig. 2 conducts, the diode current is zero, i.e., $i_{D 1}(t)=0$, and when switch $S W 1$ blocks, the diode current is equal to the inductor current, i.e., $i_{D 1}(t)=i_{L 3}(t)$. Then, the average diode current $\left\langle i_{D 1}\right\rangle_{T s}$ within switching period $T_{s}$ can be expressed in terms of duty ratio $v_{\text {cont3 }}$ and the average inductor current $\left\langle i_{L 3}\right\rangle_{T s}$. Thus

$$
\left\langle i_{D 1}\right\rangle_{T s}=\left(1-v_{\text {cont } 3}\right)\left\langle i_{L 3}\right\rangle_{T s} .
$$

Similarly, diode current $i_{D 2}$ equals zero and inductor current $i_{L 3}$ when switch $S W 2$ conducts and blocks, respectively. Then, the average diode current $\left\langle i_{D 2}\right\rangle_{T s}$ can be expressed as

$$
\left\langle i_{D 2}\right\rangle_{T s}=\left(1-v_{\mathrm{cont} 3}\right)\left\langle i_{L 3}\right\rangle_{T s}=\left\langle i_{D 1}\right\rangle_{T s} .
$$

It is clear that two diode currents have the same average value $\left\langle i_{D 2}\right\rangle_{T s}=\left\langle i_{D 1}\right\rangle_{T s}$. Assume that the average inductor current $\left\langle i_{L 3}\right\rangle_{T s}$ is well controlled to follow the rectified sinusoidal waveform $\left\langle i_{L 3}\right\rangle_{T s}=\hat{I}_{s}|\sin (2 \pi f t)|$ in phase with input voltage $v_{s}(t)$. Then, by combining $(13)(15)$, the average diode currents $\left\langle i_{D 1}\right\rangle_{T s}$ and $\left\langle i_{D 2}\right\rangle_{T s}$ can be rewritten as

$$
\begin{aligned}
\left\langle i_{D 1}\right\rangle_{T s} & =\left\langle i_{D 2}\right\rangle_{T s}=\frac{\hat{V}_{s} \hat{I}_{s} \sin (2 \pi f t)^{2}}{V_{d}^{*}} \\
& =\frac{\hat{V}_{s} \hat{I}_{s}}{2 V_{d}^{*}}-\frac{\hat{V}_{s} \hat{I}_{s}}{2 V_{d}^{*}} \cos (4 \pi f t) .
\end{aligned}
$$




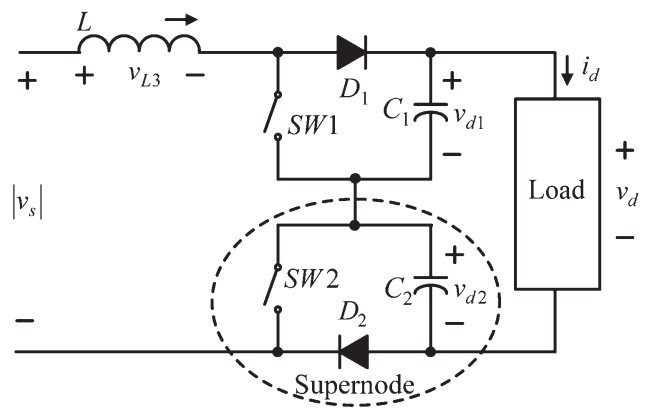

(a)

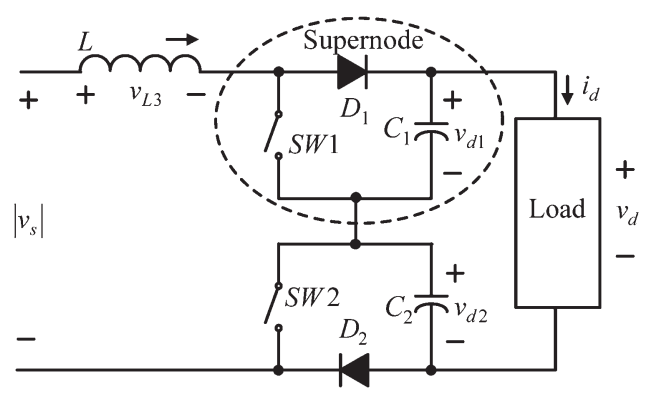

(b)

Fig. 6. Replotted circuit. (a) With lower boost unit regarded as a supernode (b) With upper boost unit regarded as a supernode.

It is clear that the ac component in (16) must flow through capacitors $C_{1}$ and $C_{2}$, respectively. The average capacitor currents $\left\langle i_{C 1}\right\rangle_{T s}$ and $\left\langle i_{C 2}\right\rangle_{T s}$ are equal to

$$
\left\langle i_{C 1}\right\rangle_{T s}=\left\langle i_{C 2}\right\rangle_{T s}=-\frac{\hat{V}_{s} \hat{I}_{s}}{2 V_{d}^{*}} \cos (4 \pi f t) .
$$

Therefore, the average voltage ripples across capacitors $C_{1}$ and $\mathrm{C}_{2}$ can be expressed as

$$
\begin{aligned}
\left\langle v_{\text {rip } 1}\right\rangle_{T s} & \approx \frac{1}{C_{1}} \int\left\langle i_{C 1}\right\rangle_{T s} d t=-\frac{\hat{V}_{s} \hat{I}_{s}}{8 \pi f C_{1} V_{d}^{*}} \sin (4 \pi f t) \\
\left\langle v_{\text {rip } 2}\right\rangle_{T s} & \approx \frac{1}{C_{2}} \int\left\langle i_{C 2}\right\rangle_{T s} d t=-\frac{\hat{V}_{s} \hat{I}_{s}}{8 \pi f C_{2} V_{d}^{*}} \sin (4 \pi f t) .
\end{aligned}
$$

As shown in Fig. 6(a), the circuit in the dashed area can be considered a supernode. Then, the remaining circuit can be referred to as a boost converter with switch $S W 1$. Similarly, the circuit in Fig. 6(b) can be seen as a boost converter with switch $S W 2$ by considering the supernode in the dashed area.

Since two boost converters have the circuit parameters and the same duty ratios and output voltage $v_{d}$ is well regulated to voltage command $V_{d}^{*}$, from the average voltage ripples in (18) and (19), the average capacitor voltages can be represented as

$$
\begin{aligned}
& \left\langle v_{d 1}\right\rangle_{T s} \approx \frac{V_{d}^{*}}{2}+\left\langle v_{\text {rip } 1}\right\rangle_{T s}=\frac{V_{d}^{*}}{2}-\frac{\hat{V}_{s} \hat{I}_{s}}{8 \pi f C_{1} V_{d}^{*}} \sin (4 \pi f t) \\
& \left\langle v_{d 2}\right\rangle_{T s} \approx \frac{V_{d}^{*}}{2}+\left\langle v_{\text {rip } 2}\right\rangle_{T s}=\frac{V_{d}^{*}}{2}-\frac{\hat{V}_{s} \hat{I}_{s}}{8 \pi f C_{2} V_{d}^{*}} \sin (4 \pi f t) .
\end{aligned}
$$

It is noted that the dc components of the average capacitor voltages in (20) and (21) are independent of the capacitance; however, the average voltage ripples are highly related to the capacitance values. Consequently, the average output voltage can be expressed as

$$
\left\langle v_{d}\right\rangle_{T s} \approx V_{d}^{*}-\frac{\hat{V}_{s} \hat{I}_{s}\left(C_{1}+C_{2}\right)}{8 \pi f C_{1} C_{2} V_{d}^{*}} \sin (4 \pi f t) .
$$

\section{Inductor Current Ripple}

To simplify the analysis of the inductor current ripple, the identical capacitance values $C_{1}=C_{2}$ and the balanced voltages are assumed. Similar to the steps for the above analysis of the average inductor voltage, the analysis is also divided into two conditions, i.e., $v_{\text {cont3 }}>0.5$ and $v_{\text {cont } 3}<0.5$. From the repeated waveforms, as shown in Fig. 5, current ripple $\Delta i_{L 3}$ can be equivalently calculated within each half switching period $0.5 T_{s}$.

$v_{\text {cont } 3}>0.5$ : In Fig. 5(a), the time taken by switching state 1 is $\left(v_{\text {cont } 3}-0.5\right) T_{s}$, and both switches conduct as shown in Fig. 4(a). The inductor voltage is $v_{L 3}=\left|v_{s}\right|$, and thus, the rising rate of the inductor current is $\left|v_{s}\right| / L$.

Similarly, the falling rate of the inductor current is $\left(0.5 v_{d}-\right.$ $\left.\left|v_{s}\right|\right) / L$ in switching state 2 when switch SW2 blocks. In Fig. 5(a), the time taken by switching state 2 is $\left(1-v_{\text {cont3 }}\right) T_{s}$. Therefore, within each half switching period $0.5 T_{s}$, the inductor current ripple $\Delta i_{L 3}$ can be expressed by either the current rising rate $\left|v_{s}\right| / L$ or the current falling rate $\left(0.5 v_{d}-\left|v_{s}\right|\right) / L$. Thus

$$
\begin{aligned}
& \Delta i_{L 3}=\frac{\left|v_{s}\right|}{L}\left(v_{\mathrm{cont} 3}-0.5\right) T_{s}=\frac{\left|v_{s}\right|}{L f_{s}}\left(v_{\operatorname{cont} 3}-0.5\right) \\
& \Delta i_{L 3}=\frac{0.5 v_{d}-\left|v_{s}\right|}{L}\left(1-v_{\mathrm{cont} 3}\right) T_{s}=\frac{0.5 v_{d}-\left|v_{s}\right|}{L f_{s}}\left(1-v_{\mathrm{cont} 3}\right) .
\end{aligned}
$$

Combining (23) and (24) yields the expression of the current ripple $\Delta i_{L 3}$ in the three-level SMR, i.e.,

$$
\begin{aligned}
\Delta i_{L 3} & =\frac{v_{d}}{L f_{s}}\left(1-v_{\operatorname{cont} 3}\right)\left(v_{\operatorname{cont} 3}-0.5\right) \\
& =-\frac{v_{d}}{L f_{s}}\left(v_{\operatorname{cont} 3}-\frac{3}{4}\right)^{2}+\frac{v_{d}}{16 L f_{s}} \leq \frac{v_{d}}{16 L f_{s}} .
\end{aligned}
$$

$v_{\text {cont }}<0.5$ : In switching state 2 , the inductor voltage is equal to $\left(\left|v_{s}\right|-0.5 v_{d}\right)$, and the current rising rate is $\left(\left|v_{s}\right|-\right.$ $\left.0.5 v_{d}\right) / L$. In Fig. 5(b), the time taken by switching state 2 is $v_{\text {cont3 } 3} T_{s}$, and the current falling rate is $\left(v_{d}-\left|v_{s}\right|\right) / L$ at switching state 4 when both switches block. Thus, the remaining time for switching state 4 is $\left(0.5-v_{\text {cont } 3}\right) T_{s}$.

Therefore, within each half switching period $0.5 T_{s}$, the inductor current ripple $\Delta i_{L 3}$ can be expressed by either the current rising rate $\left(\left|v_{s}\right|-0.5 v_{d}\right) / L$ or the current falling rate $\left(v_{d}-\left|v_{s}\right|\right) / L$. Thus

$\Delta i_{L 3}=\frac{\left|v_{s}\right|-0.5 v_{d}}{L} v_{\text {cont } 3} T_{s}=\frac{\left|v_{s}\right|-0.5 v_{d}}{L f_{s}} v_{\text {cont } 3}$

$\Delta i_{L 3}=\frac{v_{d}-\left|v_{s}\right|}{L}\left(0.5-v_{\text {cont } 3}\right) T_{s}=\frac{v_{d}-\left|v_{s}\right|}{L f_{s}}\left(0.5-v_{\text {cont } 3}\right)$. 
TABLE I

Simulated Parameters of The ThreE-Level SMR

\begin{tabular}{c|c}
\hline Input voltage & $110 \mathrm{~V}(\mathrm{rms}), 50 \mathrm{~Hz}$ \\
\hline Output voltage & $V_{d}^{*}=300 \mathrm{~V}$ \\
\hline Inductor & $0.5 \mathrm{mH}$ \\
\hline Carrier frequency & $20 \mathrm{kHz}$ \\
\hline \multirow{2}{*}{ Capacitor } & $\begin{array}{c}C_{1}=C_{2}=1880 \mu \mathrm{F} \\
\text { equivalent capacitance } \approx 940 \mu \mathrm{F} \\
\text { (for capacitance-matched condition) }\end{array}$ \\
\cline { 2 - 2 } & $\begin{array}{c}C_{1}=2240 \mu \mathrm{F}, C_{2}=1410 \mu \mathrm{F} \\
\text { equivalent capacitance } \approx 865 \mu \mathrm{F} \\
\text { (for capacitance-mismatched condition) }\end{array}$ \\
\hline Voltage controller & $k_{p}=0.1, k_{i}=20$ \\
\hline Current controller & $k_{p}=0.02, k_{i}=10$ \\
\hline
\end{tabular}

Eliminating the term $\left|v_{s}\right|$ in (26) and (27) yields the expression of current ripple $\Delta i_{L 3}$, i.e.,

$$
\begin{aligned}
\Delta i_{L 3} & =\frac{v_{d}}{L f_{s}} v_{\text {cont } 3}\left(0.5-v_{\text {cont } 3}\right) \\
& =-\frac{v_{d}}{L f_{s}}\left(v_{\text {cont } 3}-\frac{1}{4}\right)^{2}+\frac{v_{d}}{16 L f_{s}} \leq \frac{v_{d}}{16 L f_{s}} .
\end{aligned}
$$

From (25) and (28), the maximum current ripple $\Delta i_{L 3, \max }=$ $v_{d} /\left(16 L f_{s}\right)$ in the three-level SMR occurs at either $v_{\text {cont3 }}=$ $1 / 4$ or $3 / 4$. It is clear that the maximum current ripple $\Delta i_{L 3, \max }=v_{d} /\left(16 L f_{s}\right)$ is smaller than the maximum current ripple $\Delta i_{L, \max }=v_{d} /\left(4 L f_{s}\right)$ for the conventional boost-type SMR. It shows that the three-level SMR has smaller current ripple than the conventional boost-type SMR.

Additionally, the minimum current ripple for the three-level SMR is zero, i.e., $\Delta i_{L 3, \min }=0$, when control signal $v_{\text {cont3 }}$ equals either $1,1 / 2$, or 0 .

\section{Simulation Results}

In this section, some simulation results are provided, and the simulated parameters used in the three-level SMR are shown in Table I.

The capacitance-matched condition means that both capacitors have nominal capacitance $1880 \mu \mathrm{F}$. At the capacitancemismatch case, the nominal capacitance of the upper capacitor is $C_{1}=2240 \mu \mathrm{F}$, and the other is $C_{2}=1410 \mu \mathrm{F}$. It is noted that the capacitance-mismatch case is not practical; however, it is helpful for the demonstration of the MIC performance.

The results under the capacitance-matched condition and the capacitance-mismatched condition are plotted in Fig. 7(a) and (b), respectively. The yielded input current $i_{s}$ is sinusoidal in phase with input voltage $v_{s}$, and the dc components of the capacitor voltages are equal to half of voltage command $V_{d}^{*} / 2=150 \mathrm{~V}$ even in the capacitance-mismatched condition, as plotted in Fig. 7(b).

From (11) and (12), the equivalent inductor voltage $\left\langle v_{L 3}\right\rangle_{T s}$ in the three-level SMR is a function of output voltage $v_{d}$ but not of the individual capacitor voltages $v_{d 1}$ and $v_{d 2}$. With the same controller parameters, the current waveform $i_{s}$ in Fig. 7(a) is similar to the current waveform $i_{s}$ in the capacitancemismatched condition in Fig. 7(b).

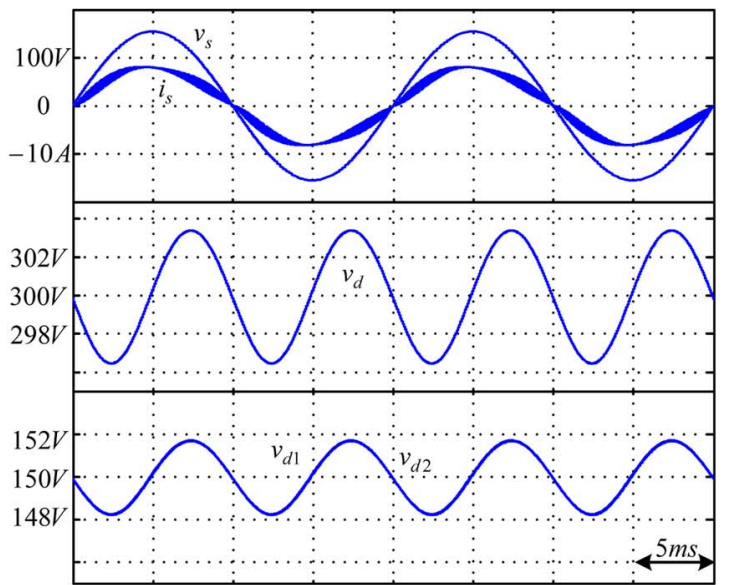

(a)

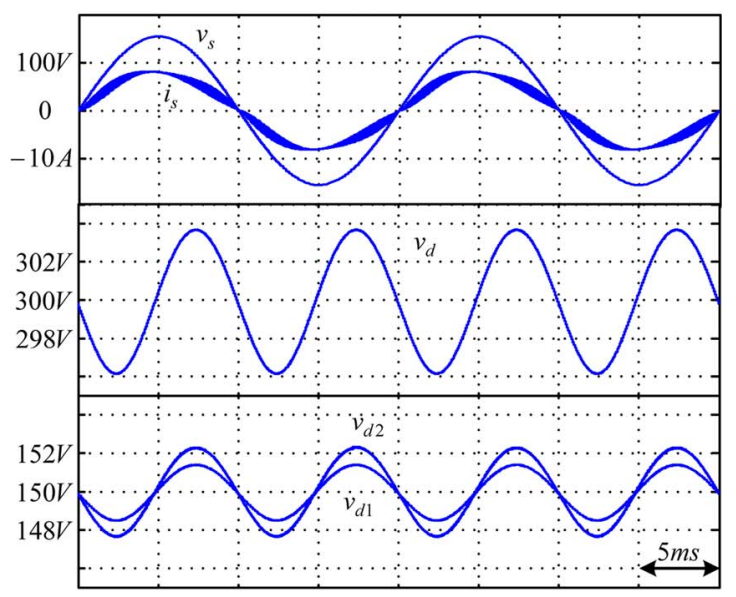

(b)

Fig. 7. Simulated results for the three-level SMR at $600 \mathrm{~W}$. (a) Under capacitance-matched condition. (b) Under capacitance-mismatched condition.

The ripple across voltage $v_{d}$ in Fig. $7($ a) is smaller than that in Fig. 7(b) due to its larger equivalent capacitance in the capacitance-mismatched condition. In Fig. 7(a), both capacitor voltages possess the same voltage ripple. In Fig. 7(b), the voltage ripple across capacitor $C_{1}$ is smaller than that across capacitor $C_{2}$ due to the mismatched capacitance values.

However, the results show that the proposed MIC is able to achieve the PFC function in the three-level SMR without the capacitor voltage balancing loop.

In order to observe the MIC performance of the transient operation, the simulated results during the load regulation are plotted in Fig. 8. The output power changes from 300 to $600 \mathrm{~W}$ due to the change of the load resistor from 300 to $150 \Omega$. In Fig. 8(a), the sinusoidal input current $i_{s}$ is always in phase with input voltage $v_{s}$, and output voltage $v_{d}$ is well regulated to the command $300 \mathrm{~V}$ during the transient period. Both the two capacitor voltages in Fig. 8(a) have the same response in this capacitance-matched condition.

The results in the capacitance-mismatched condition are plotted in Fig. 8(b). The input current waveform and the output voltage are still well controlled. In addition, capacitor voltage $v_{d 2}$ possesses larger voltage dip than capacitor voltage $v_{d 1}$ because capacitance $C_{2}$ is smaller than capacitance $C_{1}$. However, both capacitor voltages are well regulated to half command 


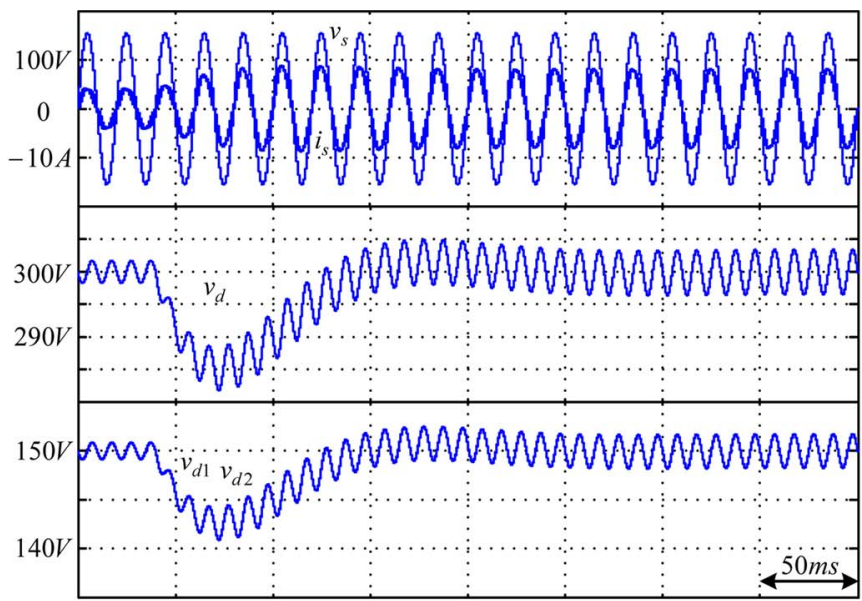

(a)

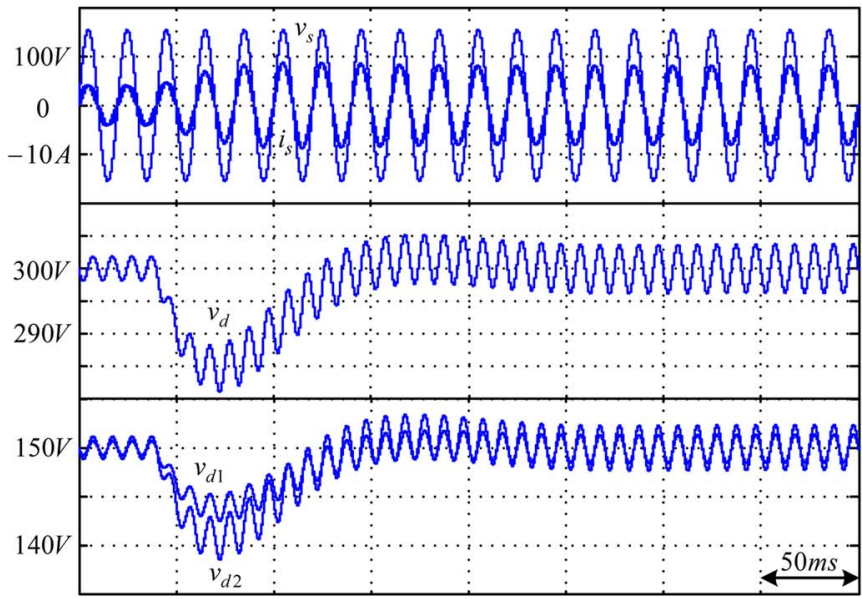

(b)

Fig. 8. Simulated waveforms during load change from 300 to $600 \mathrm{~W}$. (a) Under capacitance-matched condition. (b) Under capacitance-mismatched condition.

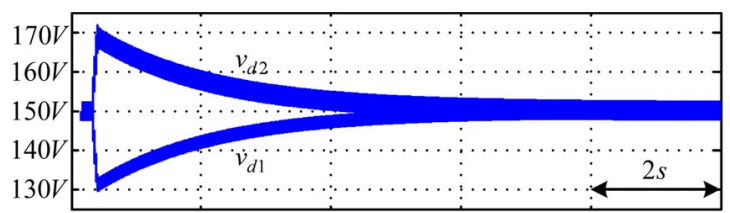

Fig. 9. Simulated waveforms when a resistor is suddenly connected across capacitor $C_{1}$ and then removed from capacitor $C_{1}$.

$150 \mathrm{~V}$ without the voltage balancing loop. It is also noted that the current waveform $i_{s}$ in Fig. 8(b) is similar to the current waveform $i_{s}$ in Fig. 8(a) even during the temporary voltage imbalance in Fig. 8(b).

To understand voltage balance between two capacitors, a $400-\Omega$ resistor is suddenly connected across capacitor $C_{1}$, and then, the resistor is removed from capacitor $C_{1}$. The simulated waveforms are plotted in Fig. 9.

The voltage ripple in capacitor voltage $v_{d 1}$ is smaller than that in voltage $v_{d 2}$, which shows that the simulation is performed under the capacitance-mismatched condition. Capacitor voltage $v_{d 1}$ quickly drops to near $130 \mathrm{~V}$ due to the suddenly connected resistor, and capacitor voltage $v_{d 2}$ increases to near $170 \mathrm{~V}$ due to the voltage control loop in MIC. After removing the connected resistor, two capacitor voltages are gradually

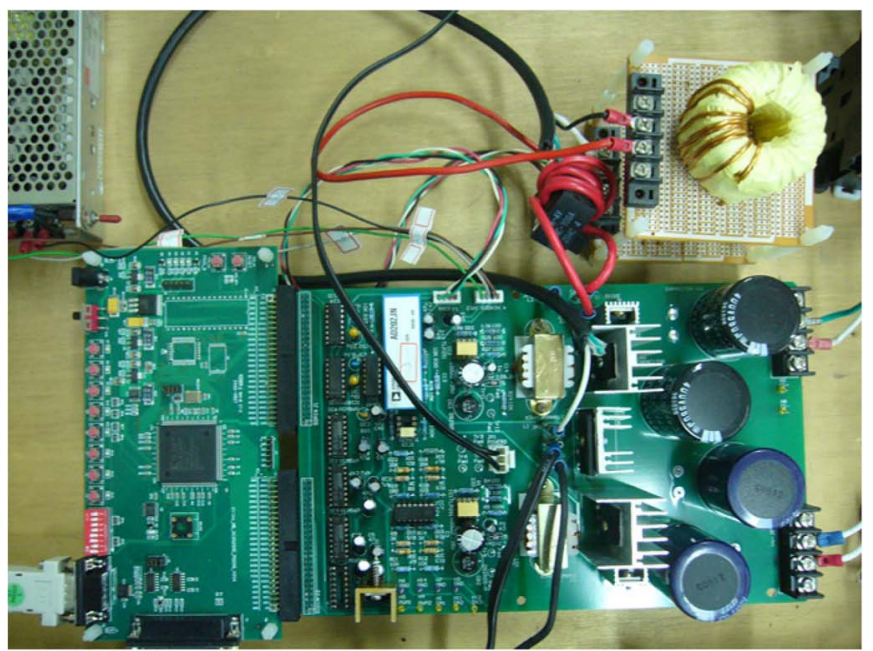

(a)

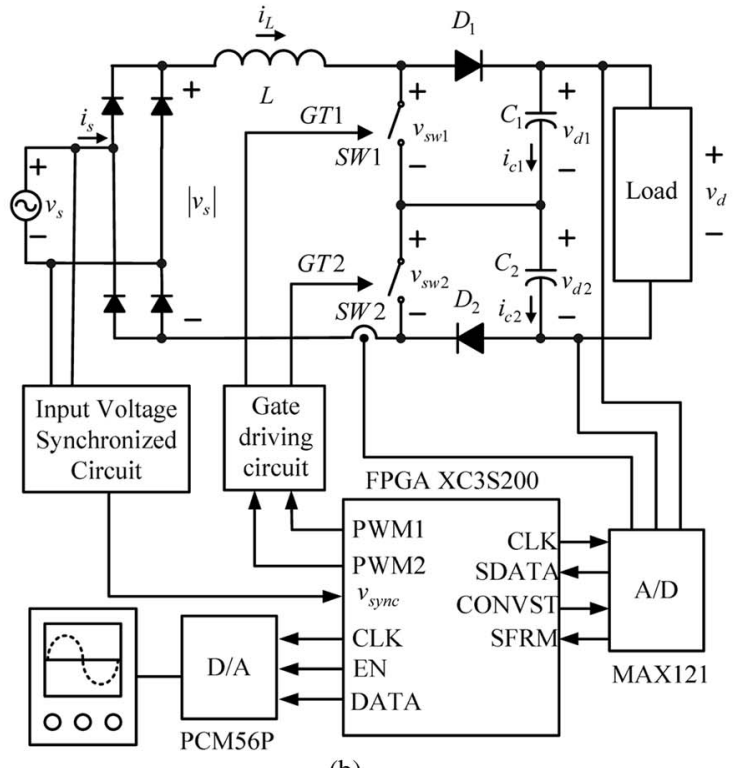

(b)

Fig. 10. (a) FPGA and the circuit board. (b) System block diagram.

balanced. It is clear that the results in Figs. 8 and 9 show that for the proposed MIC, the capacitor voltages are finally balanced without the balancing control loop and that voltage imbalance has no effect on the current waveforms.

\section{EXPERIMENTAL RESULTS}

The proposed MIC had been implemented in a fieldprogrammable gate array (FPGA)-based system, as shown in Fig. 10(a) and (b) shows the system block diagram of the experimental implementation. Due to the no-A/D and no-D/A functions in commercial FPGA XC3S200 chip, an external $\mathrm{A} / \mathrm{D}$ converter is used to sense the output voltage, and a zerocrossing detecting circuit is used to detect the zero-crossing of the input voltage. Some D/A converters are used to show the control variables of the implemented MIC in the scope. The nominal parameters are the same as those in Table I.

In practice, the mismatch of two capacitor equivalent series resistors and two duty ratio exists. Therefore, some voltage imbalance can be observed even in the capacitance-matched 


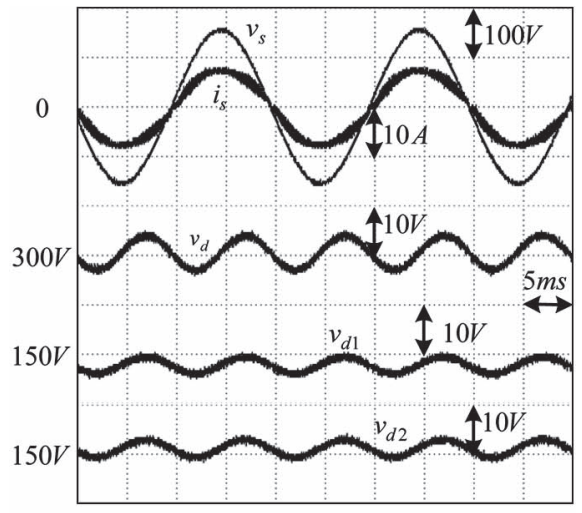

(a)

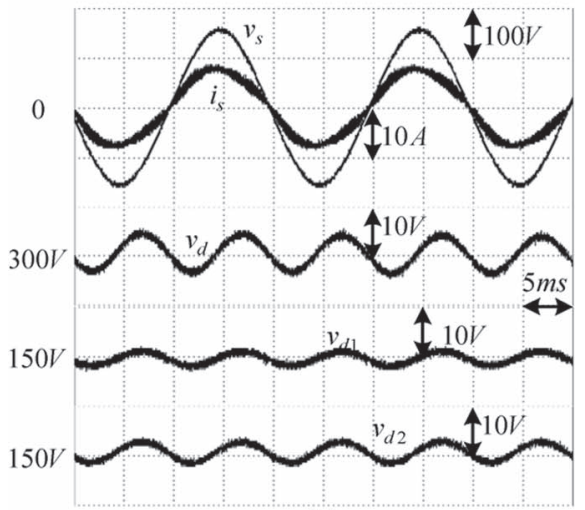

(b)

Fig. 11. Experimental results for the three-level SMR at 600 W. (a) Under capacitance-matched condition. (b) Under capacitance-mismatched condition.

TABLE II

HARMONICS OF THE INPUT CURRENT

\begin{tabular}{|c|c|c|c|c|}
\hline Harmonics & Class A & Class D & Fig. 11(a) & Fig. 11(b) \\
\hline Fundamental & $X$ & $X$ & $5.6025 \mathrm{~A}$ & $5.6791 \mathrm{~A}$ \\
\hline 3 & $4.60 \mathrm{~A}$ & $4.08 \mathrm{~A}$ & $0.2456 \mathrm{~A}$ & $0.2720 \mathrm{~A}$ \\
\hline 5 & $2.28 \mathrm{~A}$ & $2.28 \mathrm{~A}$ & $0.0508 \mathrm{~A}$ & $0.0909 \mathrm{~A}$ \\
\hline 7 & $1.54 \mathrm{~A}$ & $1.20 \mathrm{~A}$ & $0.0419 \mathrm{~A}$ & $0.0910 \mathrm{~A}$ \\
\hline 9 & $0.80 \mathrm{~A}$ & $0.60 \mathrm{~A}$ & $0.0307 \mathrm{~A}$ & $0.0806 \mathrm{~A}$ \\
\hline 11 & $0.66 \mathrm{~A}$ & $0.42 \mathrm{~A}$ & $0.0299 \mathrm{~A}$ & $0.0614 \mathrm{~A}$ \\
\hline 13 & $0.42 \mathrm{~A}$ & $0.36 \mathrm{~A}$ & $0.0283 \mathrm{~A}$ & $0.0503 \mathrm{~A}$ \\
\hline 15 & $0.30 \mathrm{~A}$ & $0.31 \mathrm{~A}$ & $0.0311 \mathrm{~A}$ & $0.0488 \mathrm{~A}$ \\
\hline 17 & $0.26 \mathrm{~A}$ & $0.27 \mathrm{~A}$ & $0.0389 \mathrm{~A}$ & $0.0606 \mathrm{~A}$ \\
\hline 19 & $0.24 \mathrm{~A}$ & $0.24 \mathrm{~A}$ & $0.0502 \mathrm{~A}$ & $0.0660 \mathrm{~A}$ \\
\hline 21 & $0.18 \mathrm{~A}$ & $0.22 \mathrm{~A}$ & $0.0509 \mathrm{~A}$ & $0.0713 \mathrm{~A}$ \\
\hline $\mathrm{PF}$ & \multicolumn{5}{|l}{} & 0.994 & 0.988 \\
\hline
\end{tabular}

condition. Fig. 11(a) and (b) shows the experimental steadystate waveforms at a $600-\mathrm{W}$ power level for the capacitancematched condition and the capacitance-mismatched condition, respectively.

Both output voltage $v_{d}$ is well regulated to $300 \mathrm{~V}$ and input current $i_{s}$ is sinusoidal in phase with input voltage $v_{s}$. Small deviation near 2-3 V from half voltage command $150 \mathrm{~V}$ in two capacitor voltages can be also found even in the capacitancematched condition, as shown in Fig. 11(a).

In addition, the same capacitor voltage ripples can be found in Fig. 11(a), and different capacitor voltage ripples can be found in Fig. 11(b). It means that the derivations of voltage ripples in (20) and (21) are verified. Table II lists the comparison of harmonics of the input current and the IEC-61000-3-2 standard.

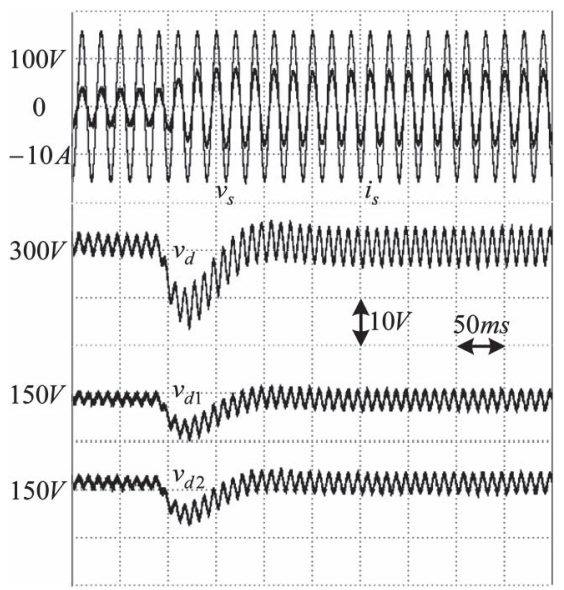

Fig. 12. Experimental waveforms under the capacitance-matched condition.

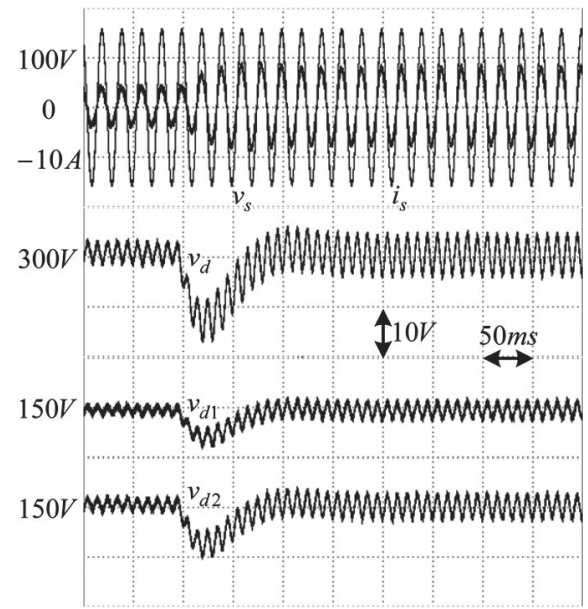

Fig. 13. Experimental waveforms under the capacitance-mismatched condition.

The current harmonics yielded by the proposed MIC is below the standard even in the capacitance-mismatched condition in Fig. 11(b).

The transient responses under the capacitance-matched condition are plotted in Fig. 12. Output voltage $v_{d}$ is well regulated to $300 \mathrm{~V}$, and input current $i_{s}$ keeps sinusoidal in phase with input voltage $v_{s}$ during the load regulation. It can be found that the experimental results in Fig. 12 are similar to the simulation results in Fig. 8(a). The voltage difference between two capacitor voltages is near $4 \mathrm{~V}$ and can be accepted in practice.

The transient responses under the capacitance-mismatched condition are plotted in Fig. 13. All three voltages $v_{d}, v_{d 1}$, and $v_{d 2}$ are well regulated during the transient period. Because capacitance $C_{1}$ is larger than capacitance $C_{2}$, capacitor voltage $v_{d 2}$ has larger voltage dip than capacitor voltage $v_{d 1}$. However, the voltages are finally balanced without the voltage balancing loop.

Note that the first two plots, i.e., $i_{s}$ and $v_{d}$, in Fig. 13 are close to those in Fig. 12. It shows that the proposed MIC is able to achieve the PFC function without the voltage balancing loop even though voltage imbalance temporarily exists.

To understand the ability to balance the capacitor voltages, a 400- $\Omega$ resistor is suddenly connected across capacitor $C_{1}$. 


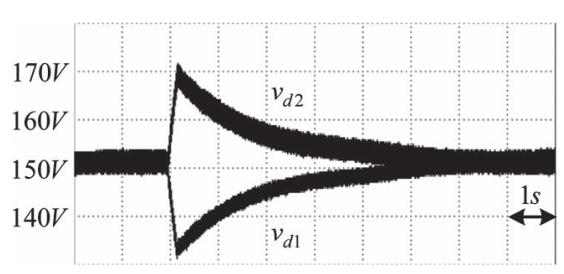

Fig. 14. Experimental waveforms when a resistor is suddenly connected across capacitor $C_{1}$ and then removed.

TABLE III

Measured InPut Power, Power Loss, EFFICIENCY, AND POWER FACTOR FOR THE CONVENTIONAL BOOST SMR AND THREE-LEVEL SMR

\begin{tabular}{|l|l|c|c|c|c|}
\hline \multirow{4}{*}{$\begin{array}{l}\text { Three- } \\
\text { level }\end{array}$} & Input power (W) & 304.3 & 406.9 & 522.0 & 617.5 \\
\cline { 2 - 6 } SMR & Output power (W) & 288.5 & 385.1 & 493.4 & 582.3 \\
\cline { 2 - 6 } & Efficiency (\%) & 94.8 & 94.6 & 94.5 & 94.3 \\
\cline { 2 - 6 } & Power loss(W) & 15.8 & 21.8 & 28.7 & 35.2 \\
\cline { 2 - 6 } & Power factor & 0.975 & 0.984 & 0.990 & 0.994 \\
\hline \multirow{4}{*}{$\begin{array}{l}\text { Boost } \\
\text { SMR }\end{array}$} & Input power (W) & 316.6 & 402.4 & 513.7 & 602.3 \\
\cline { 2 - 6 } & Output power (W) & 294.0 & 375.6 & 479.8 & 561.6 \\
\cline { 2 - 6 } & Efficiency (\%) & 92.9 & 93.3 & 93.4 & 93.2 \\
\cline { 2 - 6 } & Power loss(W) & 22.6 & 26.8 & 34.0 & 40.7 \\
\cline { 2 - 6 } & Power factor & 0.771 & 0.828 & 0.861 & 0.891 \\
\hline
\end{tabular}

Then, the connected resistor is removed. The experimental waveforms are plotted in Fig. 14.

The voltage ripple in capacitor voltage $v_{d 1}$ is smaller than that in voltage $v_{d 2}$, which shows that the waveforms are measured under the capacitance-mismatched condition. Capacitor voltage $v_{d 1}$ quickly drops to near $130 \mathrm{~V}$ due to the connected resistor, and capacitor voltage $v_{d 2}$ increases to near $170 \mathrm{~V}$ due to the voltage control loop. After removing the connected resistor, two capacitor voltages are gradually balanced. Therefore, the three-level SMR with the proposed MIC possesses the ability to balance the capacitor voltages; however, it takes several seconds to balance the voltages.

For the three-level SMR, the measured power loss, efficiency, and power factor at various power levels are tabulated in Table III. For comparison, the measured values for the conventional boost-type SMR with the same inductor and the same switching frequency are also tabulated.

From Table III, the three-level SMR yields less power loss than the conventional boost-type SMR, and the former possesses higher efficiency than the latter. It clearly shows that the three-level SMR possesses higher efficiency than the conventional boost-type SMR.

In addition, the current ripple in the three-level SMR is smaller than that in the conventional SMR, and the power factor of the three-level SMR is higher than that of the conventional SMR.

The results at $210 \mathrm{~V}(600 \mathrm{~W})$ and $265 \mathrm{~V}(400 \mathrm{~W})$ are plotted in Fig. 15(a) and (b), respectively. The results show that the proposed MIC is able to work at high line voltages.

From the provided simulation and experimental results, the proposed MIC is able to achieve the PFC function without adding the voltage balancing control loop. The results show that the three-level SMR in ac/dc applications takes several seconds to automatically balance the capacitor voltages.

Because the time taken to balance the voltages is several seconds in this case, adding the voltage balancing loop is sometimes required.

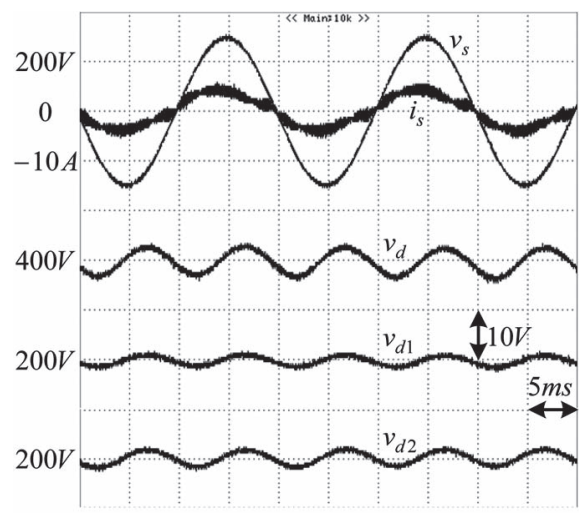

(a)

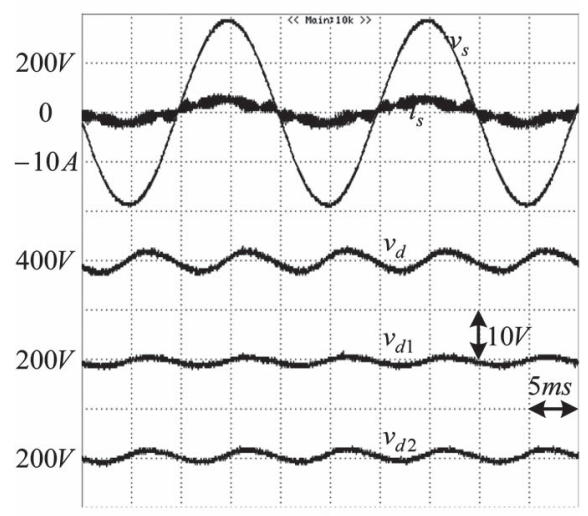

(b)

Fig. 15. Experimental results for the three-level SMR. (a) At $210 \mathrm{~V}$ and $600 \mathrm{~W}$. (b) At $265 \mathrm{~V}$ and $400 \mathrm{~W}$.

Furthermore, some other simulations and experiments for the three-level boost converter in dc/dc applications had been done; however, the results show that the converter is not able to balance the capacitor voltages automatically without the voltage balancing control loop. Hence, the proposed simple MIC cannot be extended to the three-level boost converter in $\mathrm{dc} / \mathrm{dc}$ applications because the voltage balancing loop is still required.

\section{CONCLUSION}

In this paper, the results show that the interleaved three-level SMR with the interleaved PWM scheme behaves similar to a conventional boost-type SMR. Its performance of the current shaping function does not degrade even when the two capacitor voltages are imbalanced. The MIC for the three-level SMR in ac/dc applications has been first proposed.

The proposed MIC is implemented in an FPGA-based system. The measured results show that the proposed MIC is able to achieve the desired PFC function, and the capacitor voltages are automatically balanced without adding the voltage balancing loop.

The commercial PFC ICs have the multiloop function but do not integrate the voltage balancing loop. However, based on this paper, the commercial PFC ICs can be used in the three-level SMRs if the temporary voltage imbalance is acceptable during the system operation. 


\section{REFERENCES}

[1] B. Singh, B. N. Singh, A. Chandra, K. Al-Haddad, A. Pandey, and D. P. Kothari, "A review of single-phase improved power quality AC-DC converters," IEEE Trans. Ind. Electron., vol. 50, no. 5, pp. 962-981, Oct. 2003.

[2] J. C. Crebier, B. Revol, and J. P. Ferrieux, "Boost-chopper-derived PFC rectifiers: Interest and reality," IEEE Trans. Ind. Electron., vol. 52, no. 1, pp. 36-45, Feb. 2005.

[3] S. Moon, L. Corradini, and D. Maksimovic, "Autotuning of digitally controlled boost power factor correction rectifiers," IEEE Trans. Power Electron., vol. 26, no. 10, pp. 3006-3018, Oct. 2011.

[4] A. El Aroudi, M. Orabi, R. Haroun, and L. Martinez-Salamero, "Asymptotic slow-scale stability boundary of PFC AC-DC power converters: Theoretical prediction and experimental validation," IEEE Trans. Ind. Electron., vol. 58, no. 8, pp. 3448-3460, Aug. 2011.

[5] M. Chen and J. Sun, "Feedforward current control of boost single-phase PFC converters," IEEE Trans. Power Electron., vol. 21, no. 2, pp. 338345, Mar. 2006

[6] H. C. Chen, H. Y. Li, and R. S. Yang, "Phase feedforward control for single-phase PFC boost-type SMR," IEEE Trans. Power Electron., vol. 24, no. 5, pp. 1428-1432, May 2009.

[7] H. C. Chang and C. M. Liaw, "An integrated driving/charging switched reluctance motor drive using three-phase power module," IEEE Trans. Ind. Electron., vol. 58, no. 5, pp. 1763-1775, May 2011.

[8] J. Y. Chai, Y. H. Ho, Y. C. Chang, and C. M. Liaw, "On acoustic-noisereduction control using random switching technique for switch-mode rectifiers in PMSM drive," IEEE Trans. Ind. Electron., vol. 55, no. 3, pp. 1295-1309, Mar. 2008.

[9] L. S. Yang, T. J. Liang, H. C. Lee, and J. F. Chen, "Novel high step-up DC-DC converter with coupled-inductor and voltage-doubler circuits," IEEE Trans. Ind. Electron., vol. 58, no. 9, pp. 4196-4206, Sep. 2011.

[10] W. Li and X. He, "Review of nonisolated high-step-up DC/DC converters in photovoltaic grid-connected applications," IEEE Trans. Ind. Electron., vol. 58, no. 4, pp. 1239-1250, Apr. 2011.

[11] A. Shahin, M. Hinaje, J. P. Martin, S. Pierfederici, S. Rael, and B. Davat, "High voltage ratio DC-DC converter for fuel-cell applications," IEEE Trans. Ind. Electron., vol. 57, no. 12, pp. 3944-3955, Dec. 2010.

[12] E. Ribeiro, A. J. M. Cardoso, and C. Boccaletti, "Fault-tolerant strategy for a photovoltaic DC-DC converter," IEEE Trans. Power Electron., vol. 28, no. 6, pp. 3008-3018, Jun. 2013.

[13] M. H. Todorovic, L. Palma, and P. N. Enjeti, "Design of a wide input range DC-DC converter with a robust power control scheme suitable for fuel cell power conversion," IEEE Trans. Ind. Electron., vol. 55, no. 3, pp. 1247-1255, Mar. 2008.

[14] J. M. Kwon, B. H. Kwon, and K. H. Nam, "Three-phase photovoltaic system with three-level boosting MPPT control," IEEE Trans. Power Electron., vol. 23, no. 5, pp. 2319-2327, Sep. 2008.

[15] V. Yaramasu and B. Wu, "Three-level boost converter based medium voltage megawatt PMSG wind energy conversion systems," in Proc. IEEE ECCE, 2011, pp. 561-567.

[16] M. T. Zhang, Y. Jiang, F. C. Lee, and M. M. Jovanovic, "Single-phase three-level boost power factor correction converter," in Proc. IEEE APEC, 1995, pp. 434-439.

[17] R. Greul, S. D. Round, and J. W. Kolar, "The delta-rectifier: Analysis, control and operation," IEEE Trans. Power Electron., vol. 21, no. 6, pp. 1637-1648, Nov. 2006
[18] B. R. Lin and H. H. Lu, "Single-phase power-factor correction AC/DC converters with three PWM control schemes," IEEE Trans. Aerosp. Electron. Syst., vol. 36, no. 1, pp. 189-200, Jan. 2000.

[19] B. R. Lin and H. H. Lu, "A novel PWM scheme for single-phase threelevel power-factor-correction circuit," IEEE Trans. Ind. Electron., vol. 47, no. 2 , pp. 245-252, Apr. 2000

[20] H. Wu and X. He, "Single phase three-level power factor correction circuit with passive lossless snubber," IEEE Trans. Power Electron., vol. 17, no. 6, pp. 946-953, Nov. 2002.

[21] H. C. Chen and W.-J. Lin, "MPPT and voltage balancing control with sensing only inductor current for PV-fed three-level boost-type converters," IEEE Trans. Power Electron., vol. 29, no. 1, pp. 29-35, Jan. 2014.

[22] J. R. Tsai, T. F. Wu, C. Y. Wu, and M. C. Lee, "Interleaving phase shifters for critical-mode boost PFC," IEEE Trans. Power Electron., vol. 23, no. 3, pp. 1348-1357, May 2008.

[23] P. Kong, S. Wang, F. C. Lee, and C. Wang, "Common-mode EMI study and reduction technique for the interleaved multichannel PFC converter," IEEE Trans. Power Electron., vol. 23, no. 5, pp. 2576-2584, Sep. 2008.

[24] X. Xu, W. Liu, and A. Q. Huang, "Two-phase interleaved critical mode PFC boost converter with closed loop interleaving strategy," IEEE Trans. Power Electron., vol. 24, no. 12, pp. 3003-3013, Dec. 2009.

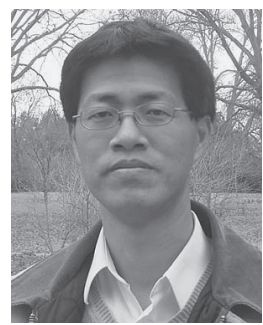

Hung-Chi Chen (M'06) was born in Taichung, Taiwan, in June 1974. He received the B.S. and Ph.D. degrees in electrical engineering from National Tsing Hua University, Hsinchu, Taiwan, in 1996 and 2001, respectively.

In October 2001, he was a Researcher with the Energy and Resources Laboratory, Industrial Technology Research Institute, Hsinchu. In August 2006, he joined the Department of Electrical and Computer Engineering, National Chiao Tung University, Hsinchu, where he is currently an Associate Professor. From September 2011 to February 2012, he was a Visiting Scholar with the University of Texas at Arlington, TX, USA. His research interests include power electronics, power factor correction, motor and inverter-fed control, and digital signal processing/microcomputer/field-programmable-gate-array-based implementation of digital control.

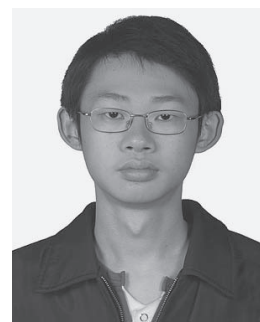

Jhen-Yu Liao was born in Taoyuan, Taiwan, in August 1986. He received the B.S. degree in mechatronic technology from National Taiwan Normal University, Taipei, Taiwan, in 2008 and the M.S. degree in electrical control engineering from $\mathrm{Na}$ tional Chiao Tung University, Hsinchu, Taiwan, in 2010, where he is currently working toward the Ph.D. degree. 